\title{
Vibrational Analysis on Hemp and Okra Fibres Mixed Glass Fiber Polyester Composite
}

\author{
Putti Venkata Siva Teja ${ }^{1}$, Badatala Ooha ${ }^{2}$, Kondeti Sravanth ${ }^{3}$ \\ ${ }^{1,2}$ Assistant Professor, Department of Mechanical Engineering, Dhanekula Institute of Engineering Technology, \\ Vijayawada, Andhra Pradesh, India- 521139. \\ ${ }^{3}$ HCL Technologies, CAE, Technical Member Chennai, Tamil Nadu, India- 600119.
}

Corresponding Author: Putti Venkata Siva Teja

\begin{abstract}
In transverse vibrations the element moves to and fro in a direction perpendicular to the direction of the advance of the wave. To determine the vibration characteristics i.e., natural frequencies and mode shapes, modal analysis is a process for a structure or a machine component while is being designed. In real life, aero planes, missiles, rockets, space vehicles, satellites, sub marines etc are modeled as freefree mechanical systems. In this paper an attempt was made to compare natural frequency for two composite materials- ladies finger with Glass fiber composite and Hemp with Glass fiber composite by taking as cantilever beams. The cantilever beam which is fixed at one end is vibrated to obtain the natural frequency, mode shapes at four different modes. A simple low cost demonstration experiment is performed in this paper by using common apparatus in order to compare theoretical, numerical (FEM analysis) profiles of two free-free thin two rectangular composite beams of dimensions $305 * 49.5 * 7$ in $\mathrm{mm}$.
\end{abstract}

Keywords: Natural frequencies, Mode shapes, Vibration characteristics, Ladies finger fiber, Hemp fiber, Glass fiber, FEM analysis, FreeFree system.

\section{INTRODUCTION}

A combination of two or more materials which results in better properties the individual components can be defined as a composite material.

The reinforcement and a matrix are the two constituents. The high strength and stiffness combined with low density, when compared with bulk materials, allowing for a weight reduction in the finished part are the main advantages of composite materials. The stiffness and strength is provided by the reinforcing phase. Reinforcement is usually a fiber or a particulate, but in most cases, it is harder, stronger and stiffer than matrix. Length of the fiber is much greater than its diameter and length-to-diameter $(\mathrm{l} / \mathrm{d})$ ratio is known as aspect ratio. Continuous fibers have high aspect ratios and discontinuous fibers have lesser. Also, continuous fiber composites normally can be made to have preferred orientation, while discontinuous have random orientation. Because of their smaller diameter, fibers produce high strength composites and they contain few defects, normally surface defects than the material produced in bulk. As per general rule, smaller the diameter of fiber, the higher its strength, but cost increases as diameter becomes smaller. Matrix is a continuous phase, which is a polymer, metal or ceramic. Polymers possess/have low stiffness and strength while metals possess/have intermediate stiffness and strength but high ductility, and ceramics have high stiffness and strength but are brittle. Several critical functions, including maintaining the fiber in proper orientation and spacing and protecting them from abrasion and environment is performed by the Matrix. In metal and polymer matrix composites that forms a strong bond between fiber and matrix, moreover matrix 
Putti Venkata Siva Teja et.al. Vibrational analysis on hemp and okra fibres mixed glass fiber polyester composite.

transmits loads from matrix to fibers through shear loading at interface, but in ceramics composites, main objective is to increase toughness rather than the stiffness and strength so that low interface bond strength is desirable. [1]

\subsection{POLYESTER RESIN:}

Polyester is the resin used in this study owing to its properties like ease of handling, dimensional stability, low cost and also good mechanical, chemical and electrical properties. Of all the resin options, polyester resins are least expensive which provides the most economical way to incorporate resin, filler and reinforcement. This is the primary resin matrix used in Sheet molding compounds and Bulk molding compounds.

The significant volume fraction of a polymer composite is formed by the matrix and it has number of critical functions like, it protects the reinforcing fibers from degradation, due to abrasion or environmental attack, it binds the reinforcement together maintains the shape of component and transfer the applied load to reinforcing fibers. Mainly thermosetting plastics, such as polyester resins, epoxy resins, phenolic resins and vinyl resins are the common matrices forms used for structural composites. Polyester resins are the most widely used resin systems, especially in marine industry. [2-4]

\subsection{GLASS FIBERS:}

Glass Fiber Reinforced Plastic (GFRP) composites are having various applications in the fields of mechanical and electrical engineering, due to its excellent properties such as lighter weight, higher specific strength and high stiffness. [10]

Glass polyester laminates, which are one of the basic construction materials, nowadays used for production of many industrial facilities. Beside their naturally high corrosion resistance, they are resistant to dynamic load, shock load and to high static loads. Due to possibility of designing their laminar structure, they can fulfill a variety of construction related requirements. [5]

Because of having high impact strength and excellent surface finish and high modulus to weight ratios compared to other fiber reinforced composite materials, glass fiber composites are extensively used in industries. Generally, there are two types of glass fibers used in fiber reinforced plastics industry namely E-glass and Sglass. There is another type called C-glass which is used in chemical applications required greater corrosion resistance to acids. [6]

\subsection{Lady's Finger Fiber:}

Okra, the scientific name of lady's finger fibers, are extracted from bark/stem of Okra bahmia plant, a plant of the Malvaceae family, botanically known as Abelmoschus esculentus. Such that, the okra stems/barks were removed and that removed stems were placed in a pit containing stagnant mud water for 6-7 days at ambient conditions. The stems then should be washed on 8th day with sufficient quantity of water till complete pulps from the fibers were detached. Then in ambient conditions this fiber was dried for 7 days. Then $5 \mathrm{ft}$. to $7 \mathrm{ft}$. long fiber will obtained. [7]

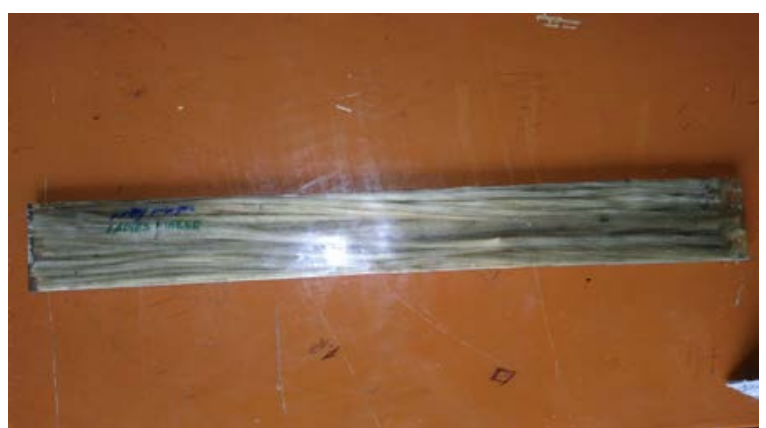

Fig: 1 shows the composite beam of ladies finger and glass fiber composition.

\subsection{HEMP FIBER:}

Hemp fiber can be easily peeled off the Xylem surface by hand or machine which are present in bundles that are as long as their stems. This stem which is fresh consists of hollow cylinder of $1-5 \mathrm{~mm}$ thick xylem covered by $100-300 \mu m$ cortex, $10-$ $50 \mu \mathrm{m}$ cambium, $20-100 \mu \mathrm{m}$ epidermis and 
2-5 $\mu$ m cuticle. Of all natural fibers, hemp yarn is strong and resistant against water. It should not be creased excessively, to avoid breakage. Hemp fiber stems have been widely preferred in the production of cords and clothing and also have potential as material of reinforcement in polymer matrix composites. [8] Nowadays hemp is used for industrial purposes including textiles, clothing, biodegradable plastics, paper, construction, health and bio fuel. However, these are extremely strong and durable and unaffected by water. [9]

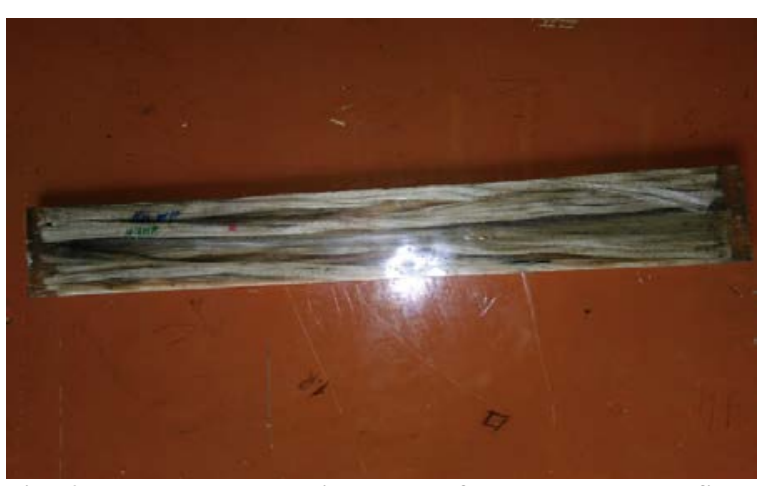

Fig: 2 shows the composite beam of Hemp and glass fiber composition.

\section{EXPERIMENTAL PROCEDURE}

The fabricated composites are tested for its natural frequency by fixing the beam at one end and leaving the other end free. At different frequencies the beam is excited, sweeping the range from low frequencies (about $2 \mathrm{~Hz}$ ) to high frequencies (up to 35 $\mathrm{Hz}$ ). By moving the potentiometer along the length of the beam the amplitude of the vibration is measured for each excitation frequency. From the measured amplitude values at four different point's comparison will be done on theoretical, numerical and analytical profile here. Figure 3 shows the experimental set up of cantilever beam. Table 1 shows the required properties of glass fiber. Table 2 shows the required properties of polyester resin. Table 3 shows the required properties of hemp fiber. Table 4 shows the required properties of Okra (ladies finger) fiber.

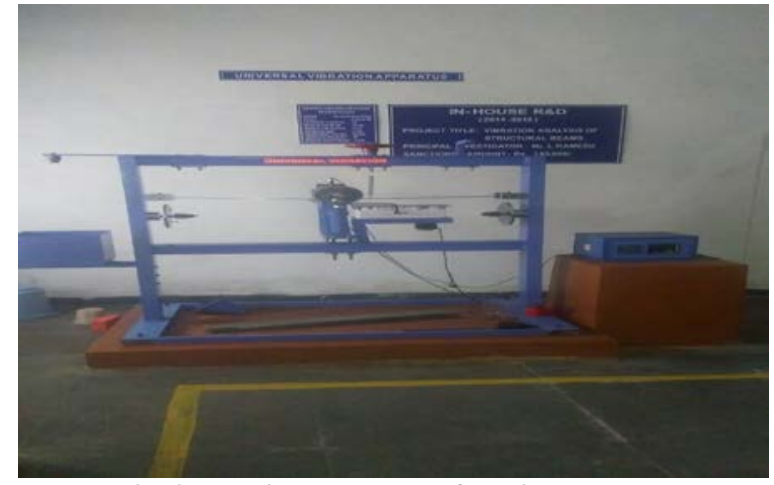

Fig: 3 Experimental set up of cantilever beam.

\section{Specifications of composite beam:}

l=Length of Beam: $302 \mathrm{~mm}$

$\mathrm{b}=$ Width of Beam: $49.5 \mathrm{~mm}$

$\mathrm{t}=$ Thickness of Beam: $7 \mathrm{~mm}$

Table1: Properties of Glass fiber

Table1: Properties of Glass fiber
\begin{tabular}{|l|l|}
\hline Property & Value \\
\hline Thickness & $7.04 \mathrm{~mm}$ \\
\hline Length & $255 \mathrm{~mm}$ \\
\hline Density $\rho$ & $2.5 \mathrm{gm} / \mathrm{cc}$ \\
\hline Poisson ratio $\mu$ & 0.23 \\
\hline Young's modulus E & $72 \mathrm{Gpa}$ \\
\hline
\end{tabular}

Table 2. Properties of polyester resin

\begin{tabular}{|l|l|}
\hline \multicolumn{1}{|c|}{ Table 2. Properties of polyester resin } \\
\hline Property & Value \\
\hline Length & $7.04 \mathrm{~mm}$ \\
\hline Density $\rho$ & $255 \mathrm{~mm}$ \\
\hline Poisson ratio $\mu$ & $1.2 \mathrm{gm} / \mathrm{cc}$ \\
\hline Young's modulus E & 0.24 \\
\hline
\end{tabular}

Table3: Properties of hemp fiber

Table3: Properties of hemp fiber
\begin{tabular}{|l|l|}
\hline Property & Value \\
\hline Thickness & $7.04 \mathrm{~mm}$ \\
\hline Length & $255 \mathrm{~mm}$ \\
\hline Density $\rho$ & $1.249 \mathrm{gm} / \mathrm{cc}$ \\
\hline Poisson ratio $\mu$ & 0.24 \\
\hline Young's modulus E & $88 \mathrm{Gpa}$ \\
\hline
\end{tabular}

Table 4: Properties of Okra fiber

Table 4: Properties of Okra fiber
\begin{tabular}{|l|l|}
\hline Property & Value \\
\hline Thickness & $7.04 \mathrm{~mm}$ \\
\hline Length & $255 \mathrm{~mm}$ \\
\hline Density $\rho$ & $1.260 \mathrm{gm} / \mathrm{cc}$ \\
\hline Poisson ratio $\mu$ & 0.24 \\
\hline Young's modulus E & $0.6 \mathrm{Gpa}$ \\
\hline
\end{tabular}

\section{FEM analysis:}

To analyze the vibrations of freefree beam, ANSYS structure package is used. In engineering analysis finite element procedures are widely using today. This procedure is mostly used in the analysis of solids and structures and heat transfer. For finding mode shapes of free-free beam in the numerical analysis, ANSYS software is used. Figure 4 Shows the hemp fibers analytical results of vibrations in $\mathrm{X}$ - 
Putti Venkata Siva Teja et.al. Vibrational analysis on hemp and okra fibres mixed glass fiber polyester composite.

direction. Figure 5 Shows the hemp fibers analytical results of vibrations in $\mathrm{Y}$ direction. Figure 6 shows the analytical results of deformation of Okra fibers in $\mathrm{X}$ - direction. Figure 7 shows the analytical results of deformation of Ladies finger fiber in Y-direction.

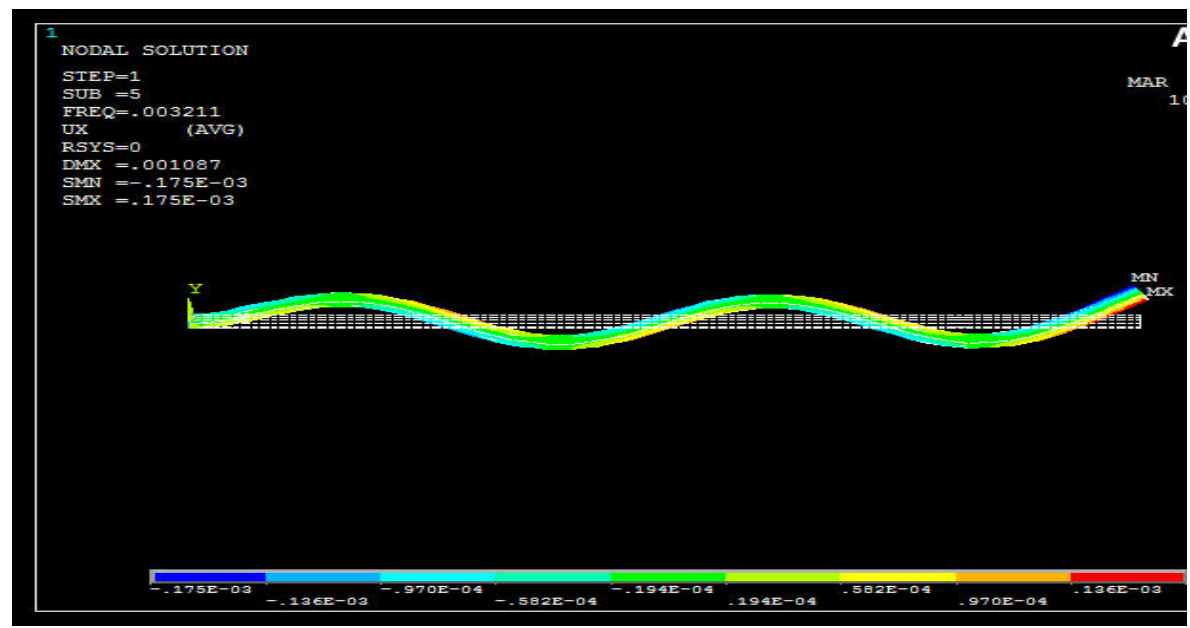

Fig4: Hemp fibers analytical results of vibrations in X-direction in ANSYS.

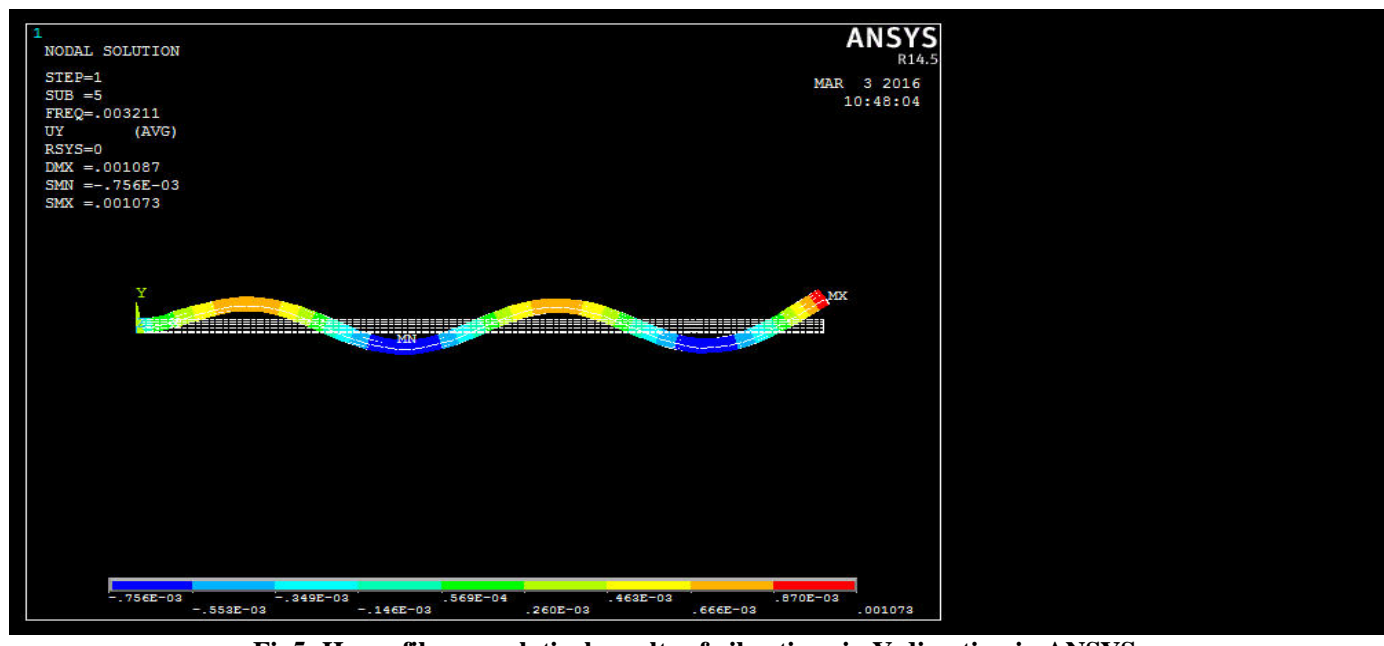

Fig5: Hemp fibers analytical results of vibrations in Y-direction in ANSYS.

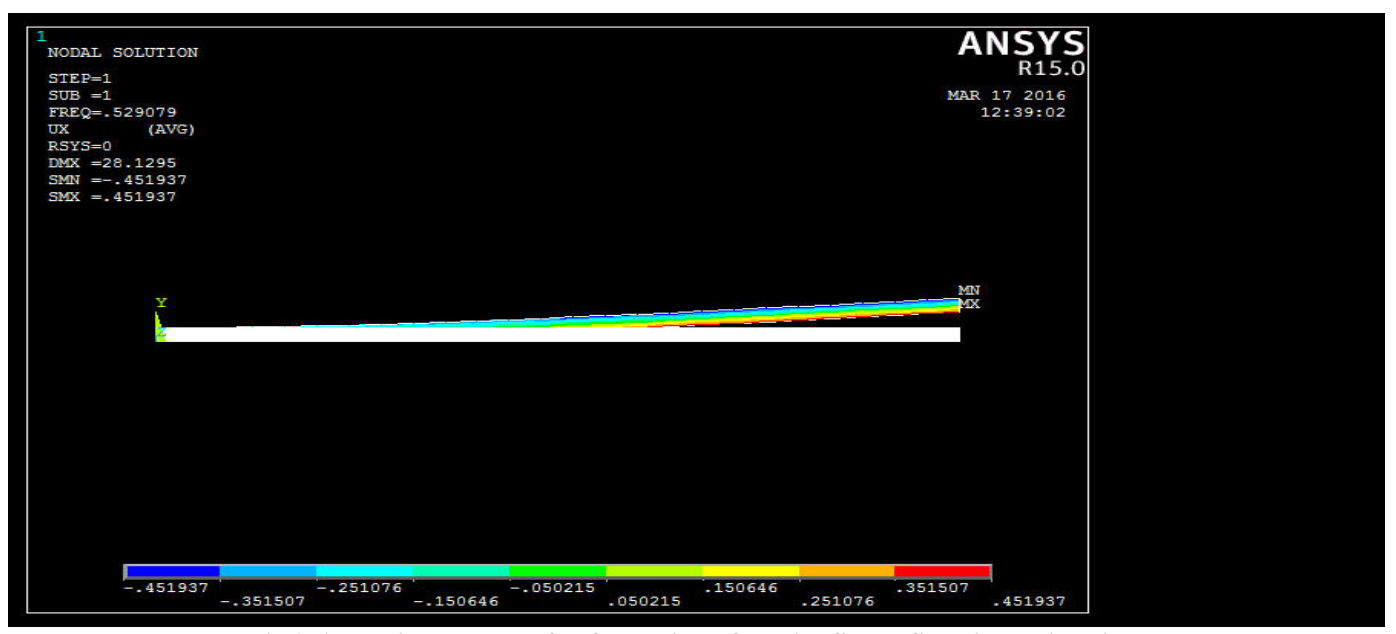

Fig6: Analytical results of deformation of Ladies finger fiber in X-direction. 
Putti Venkata Siva Teja et.al. Vibrational analysis on hemp and okra fibres mixed glass fiber polyester composite.

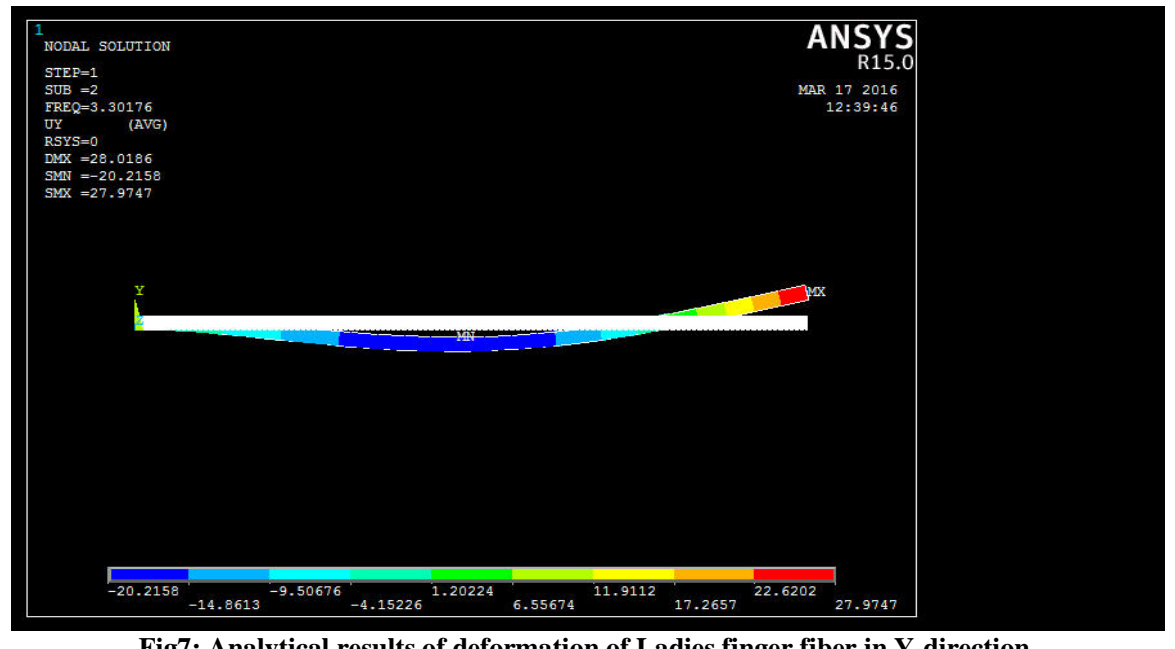

Fig7: Analytical results of deformation of Ladies finger fiber in Y-direction.

\section{RESULTS}

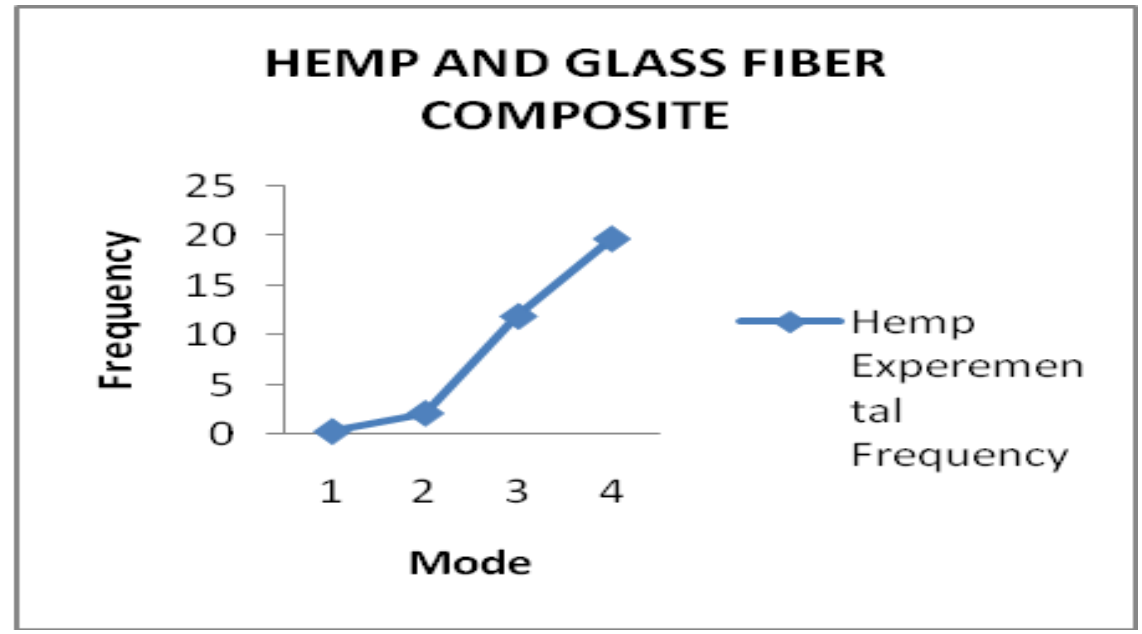

Fig8: Experimental frequencies of Hemp and Glass fiber composites at four different modes.

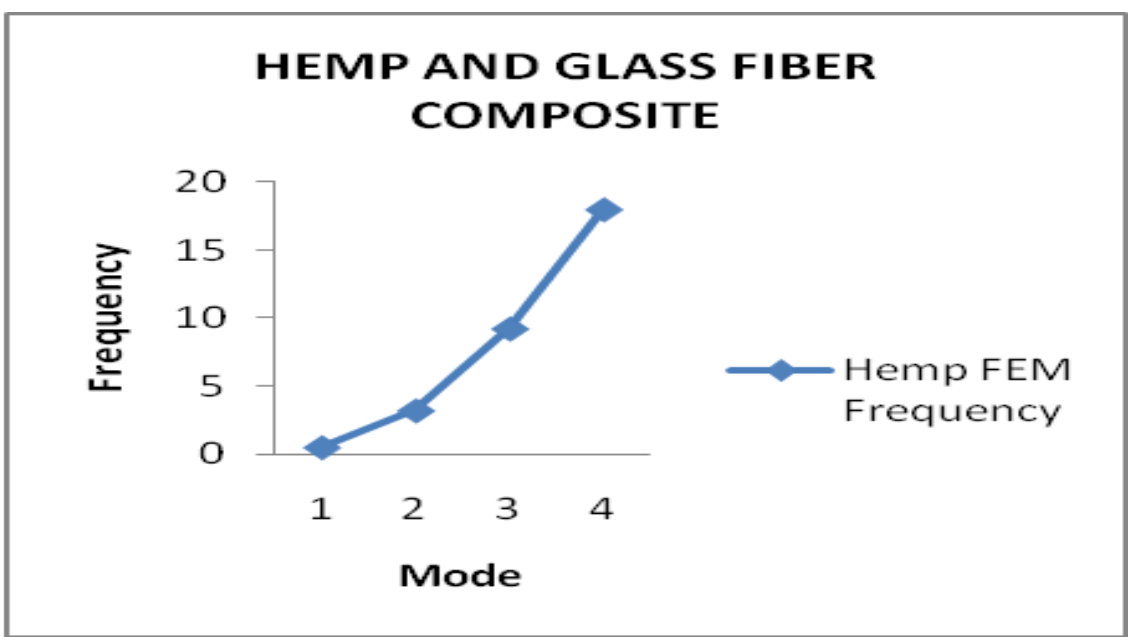

Fig9: FEM frequencies of Hemp and Glass fiber composite at four different modes.

The results which show the Experimental frequencies of Hemp and Glass fiber composites at four different modes in figure 8. Figure 9 shows the FEM frequencies of Hemp and Glass fiber composite at four different modes. Figure 10 shows the Experimental frequencies of Ladies finger and Glass composite at four different modes. Figure 11 shows the FEM frequencies of Ladies finger and Glass 
Putti Venkata Siva Teja et.al. Vibrational analysis on hemp and okra fibres mixed glass fiber polyester composite.

composite at four different modes. Figure 12 shows the Comparison between the Experimental and FEM results of HEMP and GLASS fiber composite. Figure 13 shows the Comparison between whole FEM results of both HEMP and LADIES FINGER fibers at four different modes.
Figure 14 shows the Comparison between whole experimental results of both HEMP and LADIES FINGER fibers at four different modes. Figure 15 shows the Comparison for both HEMP and LADIES FINGER fibers in both Experimental and FEM frequencies at four different modes.

\section{LADIES FINGER AND GLASS FIBER COMPOSITE}
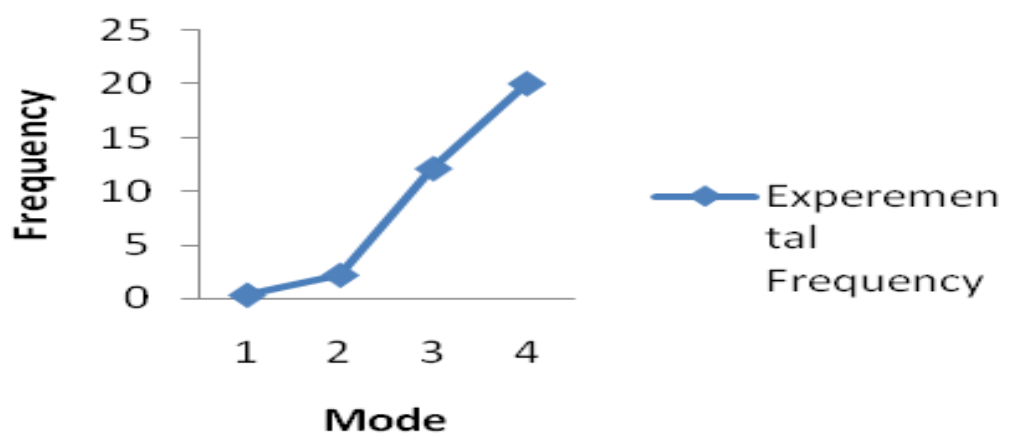

Fig10: Experimental frequencies of Ladies finger and Glass composite at four different modes

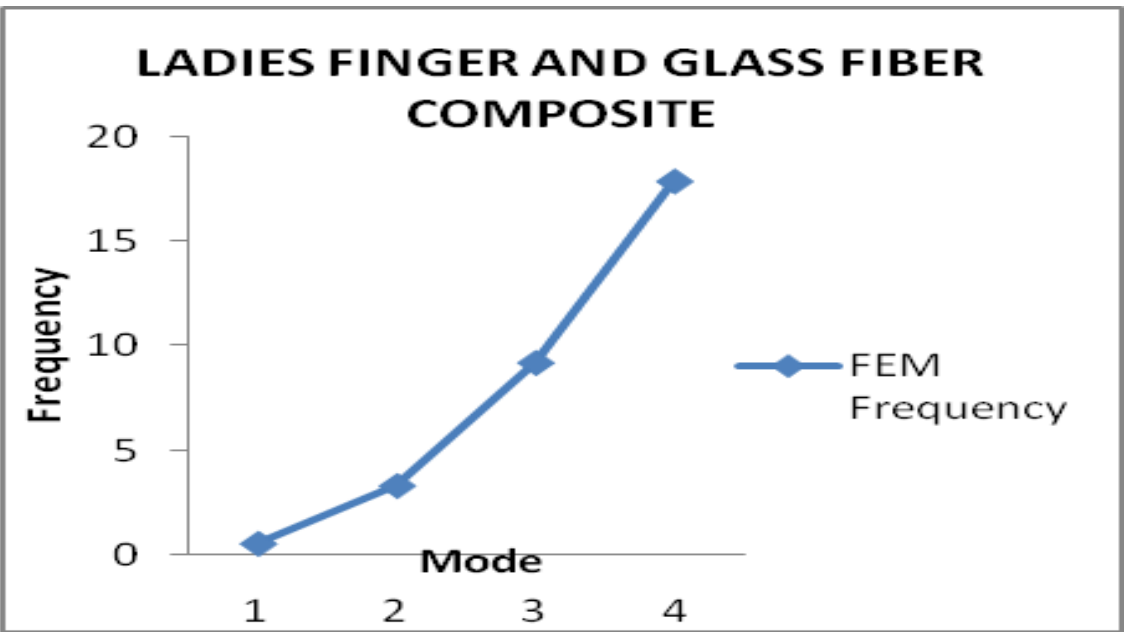

Fig11: FEM frequencies of Ladies finger and Glass composite at four different modes.

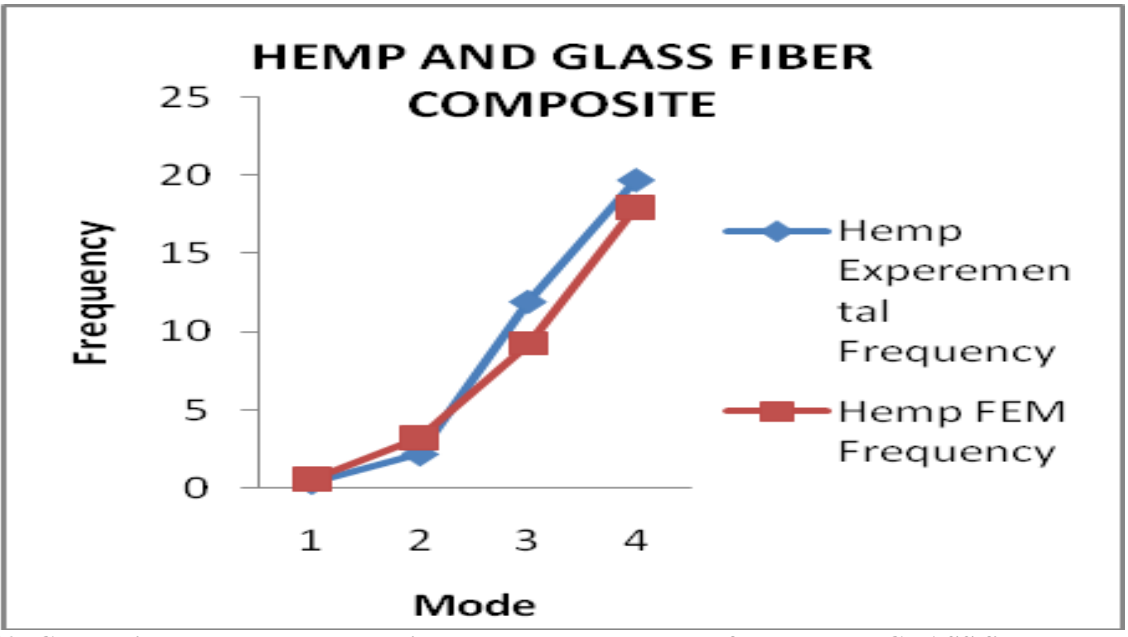

Fig12: Comparison between the Experimental and FEM results of HEMP and GLASS fiber composite. 
Putti Venkata Siva Teja et.al. Vibrational analysis on hemp and okra fibres mixed glass fiber polyester composite.

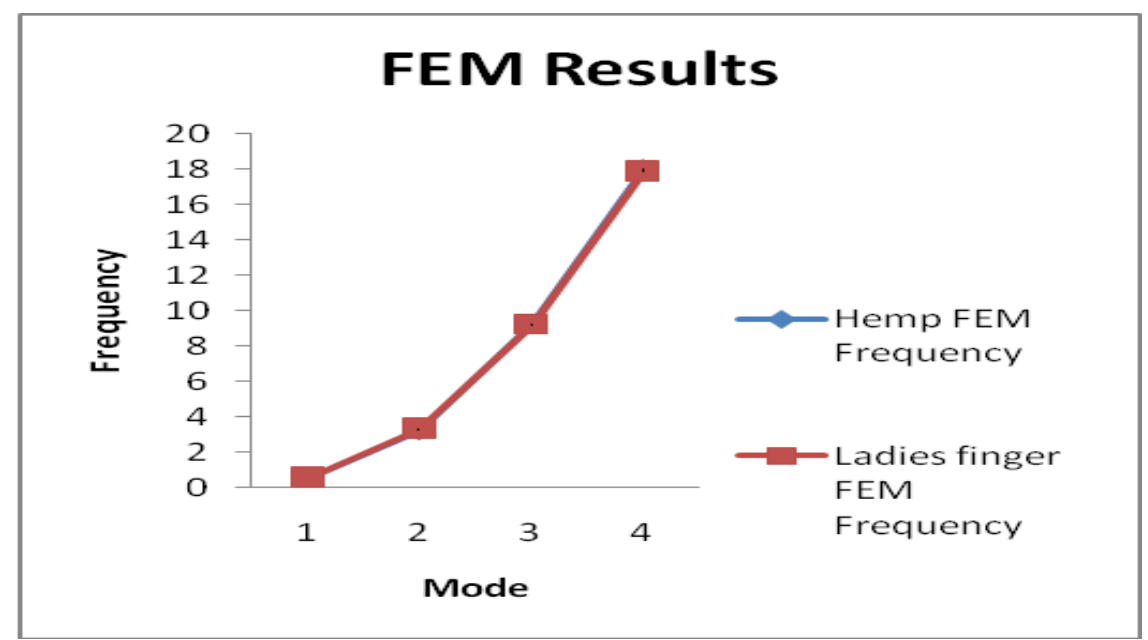

Fig13: Comparison between whole FEM results of both HEMP and LADIES FINGER fibers at four different modes.

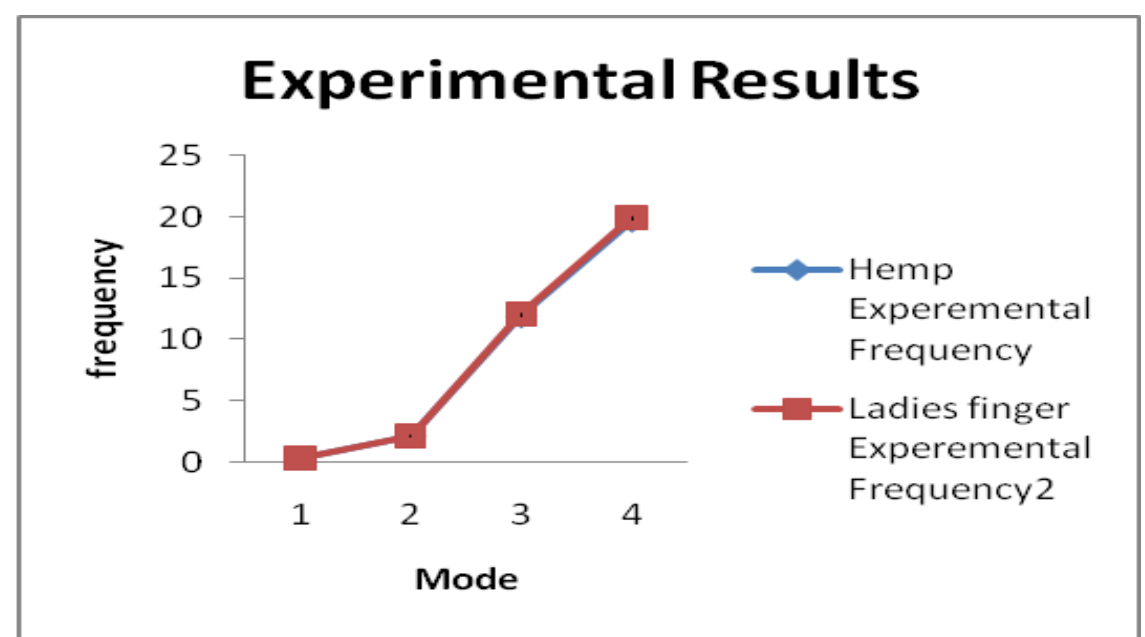

Fig14: Comparison between whole Experimental results of both HEMP and LADIES FINGER fibers at four different modes.

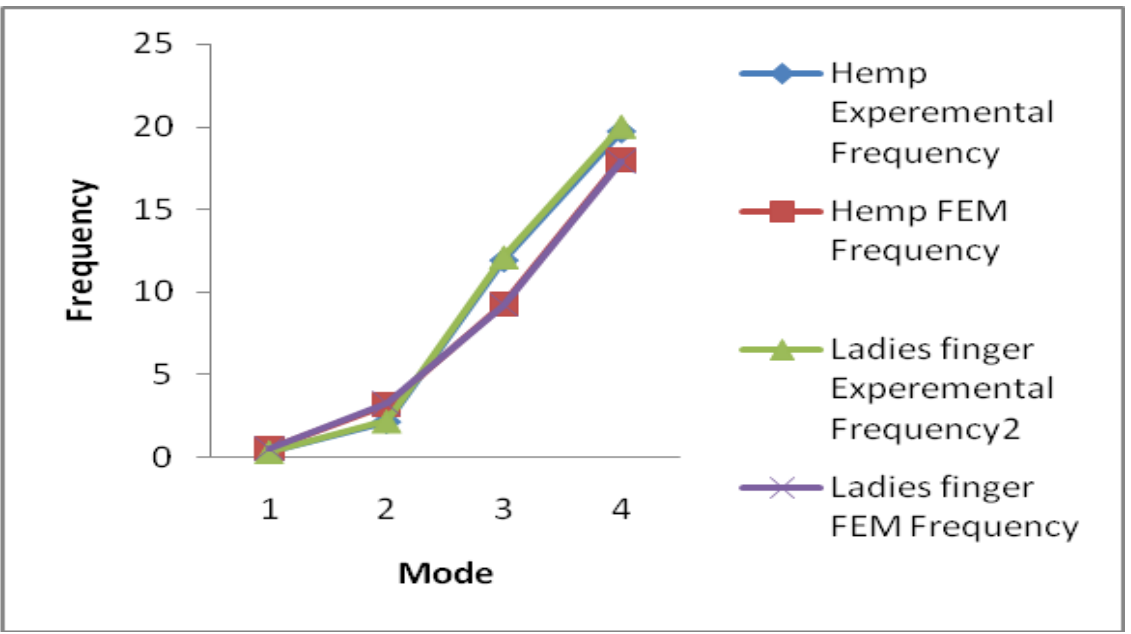

Fig15: Comparison for both HEMP and LADIES FINGER fibers in both Experimental and FEM frequencies at four different modes

\section{CONCLUSION}

- By this analysis we found out the natural frequencies of two composite fibers namely Ladies finger with glass fiber and Hemp with glass fiber.
- Using these composites within natural frequencies wherever requires gives best results.

- Today composite materials are widely using in various manufacturing sectors. 
Putti Venkata Siva Teja et.al. Vibrational analysis on hemp and okra fibres mixed glass fiber polyester composite.

So, by using these results, one can use these materials in the place of Metal composites according to their requirements.

- Moreover, these possess almost equal strength to metal composites with an additional benefit of low weight.

- But the strength and the cost depend totally upon the composition/proportions of the fibers and resins we are selected. So, anyone can extend this analysis by choosing different fiber compositions.

\section{Acknowledgement: None}

\section{Conflict of Interest: None}

\section{Source of Funding: None}

\section{REFERENCES}

1. F.C. Campbell, Structural Composite Materials, ASM international, 2010.

2. Hull D, An Introduction to Composite Materials, Cambridge University, Cambridge, P 1-57, (1992).

3. Vale C.P, the Chemistry of Unsaturated Polyesters and Allyl Resins, Chapter- 2 in Glass Reinforced Plastics, London, p 19-36, (1961).

4. Richardson T, Composites: A Design Guide, Industrial Press, New York, p 1-11, (1987).

5. J. Myalski, Properties of laminates containing polymer glass fiber recyclates,
Silesian University of Technology, Poland, 2005.

6. K. Naresh Kumar, Experimental Investigation on Mechanical Properties of Coal Ash Reinforced Glass Fiber Polymer Matrix Composites, ANITS, Volume 3, 2013.

7. Sanjay M.R, Arpitha G R, B Yogesha "Investigation on Mechanical Property Evaluation of Jute-Glass fiber reinforced polyester”, IOSR-JMCE, P-IISN:2320334X, Volume 11, Issue 4, Ver. V(Jul-Aug 2014).

8. I.V. Rijswijk and W.D Brouwer, in Natural Polymers and Composites, ed.L.H.C. Mattoso, A. Leao and E.Frollini, Sao Carlos, Brazil, 2002.

9. NNFCC Project Factsheet: Guide to building with Hemp-Lime composites, NNFCC 07-001, "National Non-Food Crops Center”, Feb 2011.

10. Putti Venkata Siva Teja, S. Prakash, B. Narasimha Prasad, Gowra Elijah "Finite Element Analysis in Drilling GFRP Composites" Indian Journal of Science and Technology, Vol 8(15), DOI: 10.17485/ijst/2015/v8i15/59588, July 2015.

How to cite this article: Teja PVS, Ooha B, Sravanth K. Vibrational analysis on hemp and okra fibres mixed glass fiber polyester composite. International Journal of Research and Review. 2021; 8(11): 55-62. DOI: https://doi.org/10.52403/ijrr.20211108 